\title{
Avanços no tratamento da hepatite pelo vírus B
}

\author{
Advances in the treatment of hepatitis B
}

Marcelo Simão Ferreira ${ }^{1}$ e Aércio Sebastião Borges ${ }^{1}$

\begin{abstract}
RESUMO
Nos últimos anos, houve um grande progresso no tratamento da hepatite B crônica. Cinco drogas são hoje aprovadas para tratamento dessa virose: intérferon $\alpha$, lamivudina, adefovir, entecavir e telbivudina. Os intérferons (convencionais ou peguilados) foram as primeiras drogas utilizadas no tratamento dessas infecções podendo levar a resposta sustentada (perda do DNA-VHB e do AgHbe) em até um terço dos casos tratados. Um grande número de análogos de nucleosídeos/nucleotídeos estão no momento, disponíveis para tratar a hepatite B; a eficácia da lamivudina, o primeiro análogo de nucleosídeo utilizado, é limitada pela elevada incidência de resistência. O adefovir tem eficácia comparável à lamivudina porém baixa freqüência de resistência. Entecavir e tenofovir também se mostram muito ativos em controlar a replicação do vírus da hepatite B, e estão associados com mínimo desenvolvimento de resistência, mesmo em tratamento prolongados. Outras drogas, tais como telbivudina, emtricitabina e clevudine, se tornarão em futuro próximo, novas armas no controle dessa virose. Co-infectados HIV/VHB representam um grupo de doentes de difícil manuseio e que hoje se beneficiam com combinações de drogas no esquema anti-retroviral potente que devem atuar em ambas as viroses. $O$ desenvolvimento de antivirais mais potentes e novas associações de medicamentos, conjuntamente com a melhor compreensão dos mecanismos de resistência do vírus da hepatite B a terapia são importantes conquistas para melhorar a eficácia do tratamento e diminuir no futuro, a carga global de portadores do vírus da hepatite $B$.
\end{abstract}

Palavras-chaves: Hepatite B. Cirrose hepática. Intérferon $\alpha$. Análogos de Nucleosídeos/nucleotídeos. Carcinoma hepatocelular.

\section{ABSTRACT}

Over the last years there has been considerable progress in the treatment of chronic hepatitis B. Five drugs are now approved for the treatment of this virosis: interferon $\alpha$, lamivudine, adefovir, entecavir and telbivudine. Interferons (conventional or PEG) were the first medicine used in the treatment of hepatitis being able to lead the persistent response (loss of DNA-HBV and of AgHbe) to up to one third of treated cases. A large number of nucleoside/nucleotide analogues are, at present, available to treat hepatitis B. The efficacy of lamivudine, the first nucleoside analogue used, is limited by the high rate of resistance. Adefovir has efficacy comparable to that of lamivudine, but with low resistance rate. Entecavir and tenofovir have also been particularly active in the control of hepatitis B virus replication and are associated with minimal resistance development, even during long treatment regimens. Other drugs, such as telbivudine, emtricitabine and clevudine, will become new treatment options in the near future. Individuals co-infected with HIV/HBV are particularly difficult to manage and are nowadays able to benefit from combinations of drugs of the HAART therapy, which should be effective towards both viruses. The development of more potent antiviral drugs as well as new drug combinations, together with a better understanding of hepatitis B virus resistance mechanisms are important milestones to improve treatment efficacy and to diminish, in the future, the global burden of hepatitis B virus.

Key-words: Hepatitis B. Liver cirrhosis. Interferon $\alpha$. Nucleoside/nucleotide analogues. Hepatocellular arcinoma.

Estima-se que aproximadamente 350 milhões de pessoas são portadoras do vírus da hepatite B (VHB) no mundo. Essa virose mostra-se amplamente distribuída em todos os continentes, predominando no Sudeste Asiático e na África, subsaariana. A infecção traz, a longo prazo, a seus hospedeiros, graves consequiências ao fígado, podendo levar à cirrose hepática, e suas complicações e ao hepatocarcinoma ${ }^{26}$. Nos últimos anos tem-se observado um avanço considerável no diagnóstico e tratamento dessa entidade. Hoje, dispomos de diversas drogas para terapia da hepatite B crônica, cinco das quais já aprovadas para uso clínico ${ }^{2831}$.

Outro tópico, de grande importância, que aqui será abordado é aquele referente aos co-infectados com o vírus da imunodeficiência humana (HIV). Sabe-se hoje que a Aids modifica a história natural da hepatite B (e C) nesses pacientes, levando à deterioração da função hepatocelular num curto espaço de tempo, diminuindo, portanto, a expectativa de vida ganha por esses doentes desde a introdução da terapia anti-retroviral de

1. Serviço de Infectologia, Hospital de Clínicas Universidade Federal de Uberlândia, Uberlândia, MG

Endereço para correspondência: Prof. Marcelo Simão Ferreira. Rua Goiás 480/500, Centro, 38400-027 Uberlândia, MG.

Tel: $55349992-0415$

e-mail: marcelosferreira@netsite.com.br

Recebido em: 03/03/2006

Aceito em: 18/07/2007 
alta potência (HAART). Nessa revisão, pretende-se apresentar os últimos avanços no diagnóstico e tratamento da hepatite $\mathrm{B}$, com ênfase nos resultados obtidos nos mais recentes estudos com as novas drogas já disponíveis em nosso país para uso nessa infecção ${ }^{28}$.

\section{HEPATITE B}

História natural e nova terminologia. Após a infecção aguda, aproximadamente 3 a $5 \%$ dos adultos e até $95 \%$ das crianças se tornam portadoras crônicas do VHB. A hepatite B crônica é um processo dinâmico com uma fase replicativa precoce com doença hepática ativa e uma fase tardia com baixa replicação viral e remissão histológica da doença. Classicamente, divide-se sua história natural em 3 fases ${ }^{19} 22263139$ : 1) fase de tolerância imune, mais comumente vista em crianças que adquiriram o VHB por transmissão perinatal ou nos primeiros anos de vida, sendo caracterizada pela positividade do AgHbs e do AgHbe, de altos níveis de carga viral (DNA-VHB), aminotransferases normais (ALT, AST) e atividade necro-inflamatória discreta com fibrose ausente ou mínima à biópsia hepática ${ }^{31}$. 2) A segunda fase, da reação imune, é caracterizada por níveis séricos de DNA-VHB menos elevados, aumentos das aminotransferases e moderada a grave atividade necro-inflamatória à biópsia com rápida progressão para a fibrose; o AgHbe é positivo (em altos títulos) nessa fase, podendo haver soroconversão para anti-Hbe em cerca de 8 a 15\% ao ano, na dependência de vários fatores (genótipo, p.ex.) ${ }^{31}$. 3) A soroconversão AgHbe $\rightarrow$ anti-Hbe marca a transição da hepatite crônica B para o estado de portador inativo do AgHbs, com baixos níveis de carga viral, aminotransferases normais, mínima ou nenhuma atividade necro-inflamatória à biópsia e boa evolução a longo prazo com, baixo risco de desenvolvimento da cirrose e hepatocarcinoma. Alguns pacientes podem, depois de períodos variáveis, soroconverterem para anti-Hbs, resolvendo a infecção de forma definitiva. Cumpre destacar, entretanto, que alguns doentes já evoluíram para cirrose por ocasião da soroconversão AgHbe $\rightarrow$ anti-Hbe e portanto podem desenvolver as complicações dessa entidade no futuro, inclusive, o hepatocarcinoma 26282963 (Figura 1).

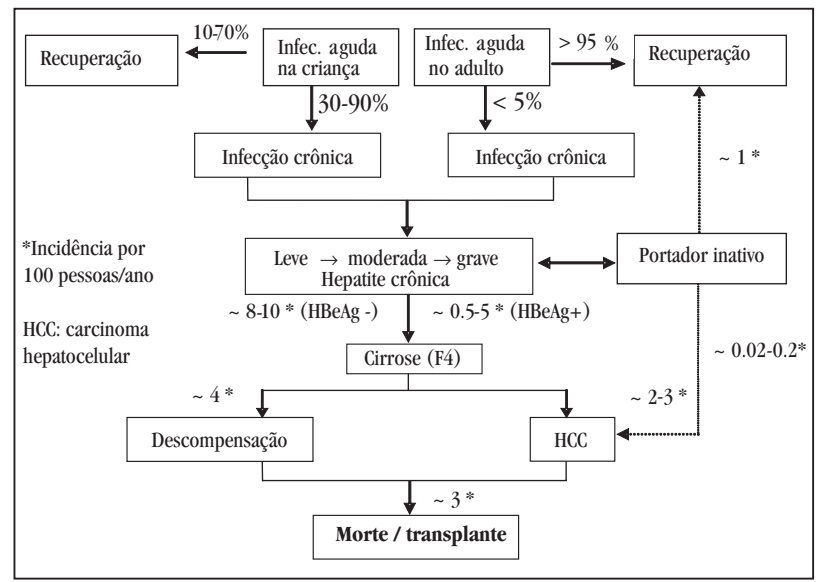

Figura 1 - Evolução da infecção pelo vírus da bepatite $B$.
Apesar da expectativa de regressão da atividade da doença após a soroconversão AgHbe $\rightarrow$ anti-Hbe, cerca de 20 a 30\% continuam a demonstrar elevados níveis de carga viral, aminotransferases elevadas e doença ativa à biópsia; esses pacientes, em geral, são portadores de mutantes do vírus B (com mutações nas regiões pré-core e promotor do core do genoma viral) que deletam a expressão do AgHbe e são hoje denominados de portadores de hepatite crônica B AgHbe negativa; essa modalidade representa o último estágio da história natural da doença e está associada a um baixo nível de remissão espontânea. Sua freqüência tem aumentado nos últimos anos, particularmente nos países mediterrâneos ${ }^{1922} 26293139$.

Desde o início da inclusão dos níveis de carga viral, no estudo dos pacientes com hepatite B crônica, tem-se adotado alguns critérios para definição de elevada ou baixa carga viral do VHB. Métodos sensíveis, como a reação em cadeia da polimerase (PCR), têm sido empregados para essa quantificação (e os resultados são expressos em cópias $/ \mathrm{ml}^{9}$ uma carga viral elevada nos pacientes AgHbe positivos consiste em se ter mais de 100.000 cópias virais/ml e nos AgHbe negativos, mais de 10.000 cópias $/ \mathrm{ml}$. Os níveis dessas cargas, que refletem a replicação do $\mathrm{VHB}$, podem, às vezes, flutuar amplamente e doentes AgHbe positivos, podem, eventualmente, apresentarem níveis menores de 100.000 cópias/ $\mathrm{ml}$. Uma proposta recente é de que a carga viral do VHB fosse expressa em unidades internacionais por $\mathrm{ml}(\mathrm{UI} / \mathrm{ml})$ com um índice de conversão de 1UI/ml para 5,6 cópias/ml; assim, nessa nova proposta, uma carga viral elevada em um paciente AgHbe positivo deverá ser maior que $20.000 \mathrm{UI} / \mathrm{ml}$ e no AgHbe negativo, maior que $2.000 \mathrm{UI} / \mathrm{ml}$. Nos portadores inativos do VHB, ela deve estar persistentemente abaixo de $2.000 \mathrm{UI} / \mathrm{ml}^{7} 3139$. A Tabela 1 mostra as novas definições e critérios diagnósticos utilizados no manuseio da hepatite crônica $B$.

Os genótipos do VHB (em número de 8, A-H), à semelhança dos genótipos do vírus da hepatite $\mathrm{C}(\mathrm{VHC})$, parecem ter uma importância crucial no manuseio da hepatite $B$, embora não estejam ainda disponíveis para uso clínico; no Brasil predominam

Tabela 1 - Definições e critérios diagnósticos utilizados na infecção pelo vírus da bepatite $B$.

\begin{tabular}{|c|c|}
\hline Definições & Critérios diagnósticos \\
\hline Hepatite crônica B (*1U = 5,6 cópias/ml) & $\begin{array}{l}\text { - } \mathrm{AgHbs} \oplus>6 \text { meses } \\
\text { - } \text { DNA-VHB sérico }>20.000 \mathrm{UI} / \mathrm{ml}^{*} \\
\text { - } \text { 个ALT/AST (persistente ou intermitente) } \\
\text { - biópsia hepática } \rightarrow \text { hepatite crônica }\end{array}$ \\
\hline Classificação da hepatite crônica B & $\begin{array}{l}\text { - } \text { AgHbe } \oplus / \text { anti-Hb } \odot \\
\text { - Hbe } \odot \text { /anti-Hbe } \oplus\end{array}$ \\
\hline Portador inativo do VHB & $\begin{array}{l}\text { - } \mathrm{AgHbs} \oplus>6 \text { meses } \\
\text { - } \mathrm{Hbe \Theta /anti-Hbe} \oplus \\
\text { - } \text { DNA-VHB sérico < } 2.000 \mathrm{UI} / \mathrm{ml} \\
\text { - } \text { ALT/AST normais } \\
\text { - } \text { Biópsia hepática normal }\end{array}$ \\
\hline Hepatite B resolvida & $\begin{array}{l}\text { - AgHbs@; Anti-Hbc } \oplus ; \text { Anti-Hbs } \oplus ; \mathrm{DNA}-\mathrm{VHB} \\
\text { sérico@; ALT normal }\end{array}$ \\
\hline
\end{tabular}

* adaptado de Keefe et al, 2006

AgHbs: antígeno de superficie do vírus B. DNA-VHB: DNA do vírus da hepatite B. AgHbe: antígeno do envelope e do vírus B. ALT/AST: Aminotransferases. 
os genótipos A e F, no Sudeste Asiático, B e C, no Sul da Europa, o genótipo D e na América do Norte e Europa Setentrional , também 0 A. As mutantes pré-core do VHB são mais comuns nos genótipos $\mathrm{B}, \mathrm{C}$ e principalmente no $\mathrm{D}$, o que explica o maior número desses doentes portadores dessas variantes no Sudeste Asiático e nos países mediterrâneos. 0 genótipo $\mathrm{C}$ está associado a doença hepática mais grave e maior frequiência de hepatocarcinoma do que o genótipo B; por outro lado, os genótipos A e B respondem melhor ao tratamento com intérferon $\alpha$ quando comparados aos C e D e o B mostra índice de soroconversão AgHbe $\rightarrow$ anti-Hbe mais precoce que o $\mathrm{C}$. Portanto, a genotipagem do $\mathrm{VHB}$ parece ser útil no manuseio dos pacientes infectados pelo VHB e poderá, no futuro, ser incorporado à prática clínica diária ${ }^{82231} 3963$.

Avaliação do paciente pré-tratamento e indicações terapêuticas. A avaliação do paciente pré-tratamento é fundamental e objetiva selecionar os indivíduos que serão tratados. Além da história e exame físico cuidadosos é importante estar à disposição do médico, todas as provas de função hepática (aminotransferases (ALT, AST), fosfatase alcalina, gamaglutamiltransferase, albumina sérica, provas de coagulação, bilirrubinas) e sorologias para o $\mathrm{VHB}$ (AgHbs, AgHbe/anti-Hbe, anti Hbc (total e IgM), anti-Hbs), VHC e HIV, estes últimos para documentar possíveis co-infecções. Também, éfundamental, hoje, incluir-se nas provas laboratoriais, a quantificação do DNA-VHB sérico, realizada através de técnicas de PCR.

Todos os pacientes devem realizar, a cada 6 meses, ultrassonografia abdominal por operador experiente e dosagem da alfafetoproteína sérica para detecção precoce de hepatocarcinoma, particularmente se o paciente apresenta cirrose hepática já estabelecida. A biópsia hepática é arma fundamental na avaliação do doente e é o indicador mais fidedigno da presença de atividade necro-inflamatória e fibrose. É essencial para afastar outras causas de doença hepática crônica, tão comuns nesses doentes (alcoolismo, esteatose). Naqueles com hepatite crônica AgHbe positivos, entretanto, sem sinais de cirrose aos métodos de imagem, com ALT e carga viral elevadas, a biópsia pode ser opcional no pré-tratamento; independente dos achados histológicos esses indivíduos já apresentam indicação formal ao tratamento medicamentoso.

Além dos portadores de hepatite crônica B AgHbe positivos, está indicado o tratamento também para: os portadores de hepatite crônica B AgHbe negativos (com ALT e carga viral elevados e biópsia com atividade necro-inflamatória importante), as manifestações extra-hepáticas da doença (glomerulonefrite, artrite, poliarterite), os cirróticos compensados ou descompensados (estes últimos, com qualquer nível de carga viral), formas graves de hepatite aguda e para os co-infectados com o HIV; em pacientes transplantados de fígado, por cirrose pelo VHB é fundamental que o tratamento seja instituído no pré-transplante (para os portadores de replicação viral ativa) e mantido no pós-transplante para impedir a infecção do enxerto pelo VHB, que é universal na ausência de terapia efetiva contra esse patógeno ${ }^{19262831394064}$.

Fatores de risco para progressão da hepatite crônica B para cirrose e hepatocarcinoma. Vários fatores tem sido considerados de risco para progressão da hepatite crônica B para a cirrose. Alguns desses fatores são ligados ao próprio VHB, como a infecção pelas mutantes pré-core e core, pelo genótipo $\mathrm{C}$ e, mais importante ainda, a persistência de carga viral elevada no decurso da doença. Autores asiáticos demonstraram que a incidência cumulativa de cirrose aumenta de 4,5\% a 36,2\% para pacientes com níveis séricos do DNA-VHB de menos de 300 cópias/ml e de > $10^{6}$ cópias $/ \mathrm{ml}$, respectivamente. A incidência de hepatocarcinoma também aumentou naqueles com carga viral mais elevada (1,3\% e 15\%, respectivamente); essa relação entre carga viral e cirrose ocorreu independente da presença do AgHbe e de elevação da ALT. Fatores ligados ao hospedeiro tais como, idade avançada, elevação persistente da ALT, ocorrência freqüente de reativações (flares) agudas e co-infecções com o VHC e HIV, também têm sido considerados de risco para progressão da doença. 0 uso crônico de álcool ou de drogas hepatotóxicas pode também acelerar o curso da infecção pelo $\mathrm{VHB}^{2} 2831374063$.

Metas e categorias de resposta à terapia antiviral na hepatite crônica B. 0 principal objetivo do tratamento da hepatite crônica B é eliminar ou suprimir significativamente a replicação do VHB e prevenir a progressão para a cirrose e o carcinoma hepatocelular ${ }^{2}$. Na luz atual dos conhecimentos, a terapia deve procurar reduzir e manter os níveis séricos do DNA-VHB os mais baixos possíveis, a ALT normal e a atividade necro-inflamatória à biópsia ausente ou de baixa magnitude. A soroconversão AgHbe $\rightarrow$ anti-Hbe é meta essencial no tratamento dos AgHbe positivos e só a sua ocorrência deve autorizar a retirada da terapia com análogos necleosídeos/nucleotídeos nesse grupo de doentes. A perda do AgHbs, com soroconversão para anti-Hbs é altamente desejável, mas só raramente pode ser atingida com os tratamentos disponíveis, a curto prazo e, portanto, não é o objetivo principal da maioria dos estudos com antivirais nessa infecção 2831394064 .

Drogas utilizadas no tratamento da hepatite B crônica. $\mathrm{Na}$ atualidade, cinco drogas tem sido aprovadas para o tratamento da infecção pelo VHB - o intérferon $\alpha 2 b$ (IFN $\alpha 2 b)$, o peg intérferon $\alpha 2 \mathrm{a}$ (PEG-IFN $\alpha 2 \mathrm{a}$ ), a lamivudina, o adefovir dipivoxil, o entecavir e mais recentemente a telbivudina; os quatro últimos são análogos de nucleosídeos/nucleotídeos utilizados por via oral, e que inibem a transcrição reversa, que ocorre durante o ciclo de replicação viral no hepatócito. Vários novos agentes antivirais e terapias imunomoduladoras estão sob investigação e não estão ainda disponíveis comercialmente. A Tabela 2 mostra as drogas disponíveis para tratamento da hepatite B crônica, suas fases de desenvolvimento e sua atividade contra o HIV, uma vez que a grande maioria dessas medicações foram inicialmente comercializadas para o tratamento de pacientes HIV positivos e só, posteriormente foram deslocadas para uso em infecções pelo VHB. Nenhuma dessas medicações consegue erradicar de maneira eficaz o VHB dos hepatócitos; como se sabe, esse vírus ao infectar a célula hepática, desloca seu genoma (DNA) para o núcleo e aí, se organiza em pequenos minicírculos de DNA covalentemente fechados (ccc DNA) que mantém a infecção intracelular e servem de molde para transcrição do RNA-pré-genômico e só podem desaparecer com a morte dos hepatócitos. Nenhum antiviral consegue a curto prazo, diminuir os níveis de ccc DNA dos 
Tabela 2 - Drogas utilizadas no tratamento da bepatite B crônica.

\begin{tabular}{lccc}
\hline Drogas & $\begin{array}{c}\text { Fases de } \\
\text { desenvolvimento }\end{array}$ & $\begin{array}{c}\text { Atividade } \\
\text { anti-HIV }\end{array}$ & $\begin{array}{c}\text { Atividade } \\
\text { YMDD }\end{array}$ \\
\hline Intérferon $\alpha$ (convencional e PEG) & aprovado & não & $\oplus$ \\
Análogos nucleosídicos & aprovada & $\oplus$ & $\odot$ \\
lamivudina & III & $\oplus$ & $\odot$ \\
emtricitabina & III & $\odot$ & $\odot$ \\
valtorcitabina & aprovada & $\odot$ & $\odot$ \\
telbivudina & II & $\odot$ & $\oplus / \odot$ \\
clevudine & aprovado & $\odot$ & $\oplus(1 \mathrm{mg} / \mathrm{dl})$ \\
entecavir & II & $\oplus$ & $\oplus$ \\
andoxovir & & & \\
Análogos nucleotídicos & aprovado & $\oplus(30 \mathrm{mg})$ & $\oplus$ \\
adefovir & II & $\oplus$ & $\oplus$ \\
pradefovir & III & $\oplus$ & $\oplus$ \\
tenofovir & I & $?$ & $\oplus$ \\
alamifovir & & & \\
\hline
\end{tabular}

YMDD: $\rightarrow$ mutante YMDD do VHB. PEG: peguilado

hepatócitos, de forma eficaz, e seriam necessários muitos anos de tratamento com análogos de nucleosídeos/nucleotídeos, por exemplo, para se conseguir a erradicação desses minicírculos dos núcleos das células hepáticas. Será analisada cada droga antiviral separadamente, mostrando-se os resultados dos estudos que comprovaram a atividade de cada uma delas na hepatite B crônica. A Tabela 3 mostra a atividade antiviral de todas as drogas efetivas no tratamento da hepatite B crônica AgHbe positiva, tendo sido os dados copilados de vários estudos da literatura 2831394064 .

Intérferon $\alpha$ : intérferon $\alpha$ tem sido usado há vários anos no tratamento da hepatite B crônica. Essa citocina atua no VHB por dois mecanismos; primeiro por ação antiviral direta através de inibição da síntese do DNA viral e segundo, por uma ação imunomoduladora, que se expressa pelo aumento dos antígenos de histocompatibilidade de classe I na membrana dos hepatócitos e através da estimulação da atividade de linfócitos T auxiliares e natural killer. Na sua formulação convencional, não peguilada, é utilizado na dose de 5 milhões de unidades, administrada diariamente, por via subcutânea, por um período de 4 a 6 meses; doses de 10 milhões de unidades, três vezes por semana, também podem ser administradas, com resultados satisfatórios. A droga promove rápido bloqueio da replicação viral (com diminuição dos níveis séricos do DNA-VHB) e cerca de 2 a 3 meses após início do tratamento, verifica-se em cerca de $70 \%$ dos casos, elevação das aminotransferases, fato que reflete o aumento da atividade imune sobre os hepatócitos infectados. Muitos estudos controlados utilizando essa medicação no tratamento da hepatite B tem sido publicados; em uma metanálise desses estudos, a resposta virológica com queda do DNA-VHB sérico, comparado ao placebo, foi de $37 \%$ vs $17 \%$, a perda do AgHbe com soroconversão para anti-Hbe foi de $33 \%$ vs $12 \%$ no grupo placebo e a perda do AgHbs foi de $8 \%$ vs $2 \%$ no grupo placebo. Portanto, o benefício dessa medicação é alcançada em apenas um terço dos pacientes tratados não tendo sido observado vantagens no prolongamento do tempo de tratamento. Baixos níveis séricos do DNA-VHB no pré-tratamento e altos níveis de ALT são preditivos de boa resposta a essa medicação. Pacientes que adquiriram a infecção pelo VHB ao nascimento ou nos primeiros anos de vida, apresentam imunotolerância ao vírus e respondem mal a terapia com IFNo. Naqueles portadores de hepatite crônica B AgHbe, a terapia com IFN $\alpha$ deve ter duração maior, de 12 a 24 meses; a resposta virológica ao final do tratamento varia de 40 a $90 \%$, mas os índices de recidivas são elevados, da ordem de 30 a $90 \%$; a resposta virológica sustentada é, portanto, de 15 a 25\%; nesses pacientes, que alcançaram a resposta virológica, pode haver perda do AgHbs, a longo prazo em até 32\% dos casos ${ }^{1931} 3940$.

Formulações peguiladas (PEG-IFN $\alpha 2 a)$ também já foram utilizadas no tratamento da hepatite crônica B. Essas novas apresentações de IFN $\alpha$ apresentam longa meia-vida e podem ser administradas uma vez por semana apenas, promovendo maior conforto ao paciente; um estudo que utilizou essa medicação em pacientes AgHbe positivos, por 24 semanas, em doses de 90, 180 e $270 \mu \mathrm{g} / \mathrm{semana}$ mostrou queda do DNA-VHB abaixo de 500.000 cópias/ml, normalização da ALT e perda do AgHbe em 19 a 28\% dos pacientes, comparados com $12 \%$ naqueles que receberam intérferon convencional (IFN $\alpha 2 a$ ). Outros estudos utilizaram a formulação peguilada do IFNo2a isolada e associada a lamivudine em pacientes AgHbe positivos e AgHbe negativos, e os resultados desses estudos serão analisados posteriormente 283031334140 .

\begin{tabular}{|c|c|c|c|c|c|}
\hline Drogas & $\begin{array}{c}\text { Dose/dia } \\
\text { (por } 48 \text { sem) }\end{array}$ & $\downarrow$ DNA-VHB & $\begin{array}{l}\text { DNA VHB } \\
\text { PCR } \odot(\%)\end{array}$ & $\begin{array}{c}\text { e/anti-e } \\
(\%)\end{array}$ & $\begin{array}{c}\mathrm{R}(1 \text { ano }) \\
(\%)\end{array}$ \\
\hline Intérferon $\alpha$ & 480-960 UM & $\odot$ & 23,0 & 25,0 & $\odot$ \\
\hline PEG-IFN $\alpha 2^{\mathrm{a}}$ & $180 \mu \mathrm{g} / \mathrm{sem}$ & $-4,5$ & 25,0 & 27,0 & $\odot$ \\
\hline Lamivudina & $100 \mathrm{mg}$ & $-4,5 / 5,8$ & 40,0 & 20,0 & 16,0 \\
\hline Adefovir & $10 \mathrm{mg}$ & $-3,57$ & 21,0 & 12,0 & 0 \\
\hline Entecavir & $0,5 \mathrm{mg}$ & $-6,98$ & 69,0 & 21,0 & $0-6,0$ \\
\hline Entecavir (YMDD) & $1 \mathrm{mg}$ & $-5,06$ & 26,0 & 4,0 & 6,0 \\
\hline Telbivudine & $600 \mathrm{mg}$ & $-5,49$ & 61,0 & 31,0 & 4,4 \\
\hline Emtricitabina & $200 \mathrm{mg}$ & $-2,92$ & 55,0 & 23,0 & 9,0 \\
\hline Tenofovir & $300 \mathrm{mg}$ & $-4,5 / 4,9$ & 86,0 & 25,0 & $\odot$ \\
\hline Clevudine & $30 / 10 \mathrm{mg}$ & $<5000 *$ & 68,0 & 20,0 & $\odot$ \\
\hline
\end{tabular}

$\mathrm{R} \rightarrow$ Resistência; YMDD: mutante resistente à lamivudina. DNA-VHB: DNA do vírus $\mathrm{B}$

Odado não disponível. PCR: reação em cadeia da polimerase. * $\left(\log _{10 ;} \operatorname{cop} / \mathrm{ml}\right)$ 
Praticamente, todos os pacientes experimentam efeitos adversos durante a terapia com IFN $\alpha$ convencional ou peguilado; entre eles, destacam-se cefaléia, febre baixa, fadiga, anorexia, depressão, alopécia e bloqueio da hematopoiese na medula óssea (leucopenia, plaquetopenia). 0 uso de acetaminofen, precedendo a administração da droga, diminui a frequiência de efeitos colaterais; estes tendem a diminuir com a continuidade do tratamento. 0 uso de eritropoietina recombinante e fatores estimuladores de colônias de granulócitos estarão indicados em situações de anemia e/ou leucopenia intensas produzidas pela $\operatorname{droga}^{1928313640}$.

Lamivudina: a lamivudina foi o primeiro análogo nucleosídico utilizado no tratamento da hepatite crônica $\mathrm{B}^{3}$. A droga é utilizada por via oral na dose de 100 a $150 \mathrm{mg} / \mathrm{dia}$ dependendo da formulação empregada. Em pacientes AgHbe positivos, um ano de uso de lamivudina resulta em melhora histológica (52\% dos casos), queda do DNA-VHB sérico (44\% dos casos), soroconversão AgHbe $\rightarrow$ anti Hbe (17\% dos casos) e normalização da ALT ( $41 \%$ dos casos); se a droga é suspensa antes da soroconversão, todos os pacientes recidivam, com retorno da replicação viral; portanto, tratamento a longo prazo é necessário na maioria dos doentes ${ }^{19} 43$.

A soroconversão aumenta com a duração do tratamento, podendo chegar a 50\% após 5 anos de uso da droga, e mostra relação direta com os níveis aumentados de ALT pré-tratamento; quando esta enzima se apresenta com valores, antes do início da terapia, maiores que cinco vezes o limite superior da normalidade, a soroconversão AgHbe-anti Hbe pode ocorrer em até 56\% dos casos. Infelizmente, a incidência de resistência do VHB a lamivudina (no lócus YMDD da polimerase viral) aumenta com a duração da terapia, sendo de $14 \%$ no $1^{\circ}$ ano e $70 \%$ no $5^{\circ}$ ano de us $0^{24} 43$. A resistência à lamivudina durante o tratamento pode ser detectada através do aumento da carga viral (subida de $1 \log ^{10}$ depois da queda inicial), elevação da ALT' e surgimento de sintomas clínicos em alguns pacientes; nestes, a elevação das aminotransferases pode ser intensa e grave, levando ao comprometimento da função sintética do órgão e à descompensação da doença ${ }^{24} 313943$. Fatores preditivos de resistência a lamivudina incluem altos níveis de DNA pré-tratamento; sexo masculino e elevado índice de massa corporal.

Em pacientes AgHbe negativos, cerca de dois terços, mostram resposta bioquímica, histológica e virológica após 6-12 meses de terapia. Entretanto, a maioria dos pacientes recidivam, após a retirada do tratamento ou após o desenvolvimento de resistência à lamivudina. Um estudo recente sugere que a administração de lamivudina pode ser suspensa após 2 anos, em pacientes com níveis de DNA-VHB persistentemente indetectáveis, com baixos níveis de recidivas, mas esses dados precisam ser confirmados por outros estudos ${ }^{317}$. Tratamentos de longa duração podem manter níveis normais de ALT e DNA-VHB sérico baixo (< 400 cópias/ml), entretanto, se houver desenvolvimento de resistência (mutantes no lócus YMDD), esses valores podem alterar substancialmente. Somente $40 \%$ dos pacientes mantém esses parâmetros normais após 30 meses de terapia. Diante desses fatos, lamivudina parece ser uma droga de uso limitado na hepatite crônica AgHbe negativa. Por outro lado, é bem tolerada e tem excelente perfil de segurança ${ }^{19242831363940}$.

Adefovir-dipivoxil: adefovir é um análogo nucleotídico da adenosina monofosfato; 0 adefovir dipivoxil é a prodroga oral do adefovir; no organismo é convertido em difosfato, um metabólito intracelular que interage com a polimerase do $\mathrm{VHB}^{1431}{ }^{36}$. A dose utilizada é de $10 \mathrm{mg} /$ dia por via oral; em doses maiores $(30 \mathrm{mg} /$ dia) tem atividade também sobre o HIV, mas é potencialmente nefrotóxica e portanto, não tem indicação como droga antiretroviral. Em pacientes AgHbe positivos, um ano de tratamento com essa droga resultou em melhora histológica e redução nos níveis séricos do DNA-VHB e elevados índices de soroconversão AgHbe $\rightarrow$ anti-Hbe. Quando se prolonga $o$ tratamento acima de um ano, os benefícios são ainda maiores. Após 144 semanas de terapia com essa droga, $53 \%$ perderam o AgHbe, $46 \%$ soroconverteram para anti-Hbe, $48 \%$ negativaram os níveis séricos do DNA-VHB e $80 \%$ normalizaram as aminotransferase ${ }^{1440}$. Em portadores de hepatite crônica AgHbe negativa, o uso de adefovir por longos períodos ( 5 anos de tratamento) levam a normalização da ALT em $70 \%$ dos pacientes e queda do DNA-VHB $\left(<3 \log _{10}\right)$ em $67 \%$ dos doentes; $5 \%$ desses indivíduos perderam o AgHbs e soroconverteram para anti-Hbs. A melhora histológica foi comprovada na maioria dos tratados $^{142531363943}$. O perfil de segurança da droga é elevado e a nefrotoxicidade nessa dosagem é muito rara ( $8 \%$ na dose de $30 \mathrm{mg} /$ dia). 0 desenvolvimento de resistência ao adefovir no primeiro ano de tratamento é excepcional, mas após 5 anos de uso da medicação, 29\% desenvolvem mutações de resistência (N236T e A181V/T), que se refletem por aumento dos níveis de DNA-VHB séricos e da ALT25. A durabilidade da resposta após a retirada do tratamento ainda permanece obscura, e a recidiva ocorre quase sempre quando a medicação é retirada antes da soroconversão AgHbe $\rightarrow$ anti-Hbe; mesmo após esta ter ocorrido, é prudente manter a droga por pelo menos 6 meses antes de sua suspensão; essa conduta é válida para os pacientes que usam também lamivudina ou outro análogo de nucleosídeo/ nucleotídeo. Nos pacientes AgHbe negativos, a droga deve ser mantida o maior tempo possível ( $>5$ anos), uma vez que sua suspensão levaria à recidiva na grande maioria dos casos. Todos pacientes tratados devem ser monitorados a cada 6 meses com dosagem dos níveis séricos de ALT e do DNA-VHB, para avaliação da resposta ao tratamento e detecção de eventual resistência ao medicamento ${ }^{14252831363943}$.

Entecavir: essa droga é o mais potente inibidor da DNA polimerase do VHB; no organismo humano, é fosforilado em trifosfato (composto ativo) pelas cinases celulares. É utilizado na dose de $0,5 \mathrm{mg} /$ dia, por via oral; na dose de $1 \mathrm{mg} /$ dia é ativo também em cepas resistentes à lamivudina (mutantes YMDD) ${ }^{42831363956 .}$ Nos pacientes AgHbe positivos, 48 semanas de tratamento com esta droga, comparada com a lamivudina, $100 \mathrm{mg} /$ dia, resultou em significativa melhora histológica $(72 \%$ vs $62 \%)$, redução significativa do DNA-VHB $\left(-6,9 v s-5,4 \log _{10}\right)$, indetectabilidade do DNA-VHB sérico mais freqüente (67\% vs 36\%) e normalização da ALT (68\% vs 60\%); os índices de soroconversão AgHbe-antiHbe foram praticamente iguais para ambas as drogas ( $21 \% v s$ 18\%); esses resultados foram mantidos após 96 semanas de 
terapia, resultando em significativo índice de indetectabilidade do DNA-VHB sérico (80\%) e elevado índice de soroconversão AgHbe $\rightarrow$ anti-Hbe $(31 \%)^{5}$. Em pacientes com hepatite crônica AgHbe negativos, o tratamento com entecavir por 48 semanas resultou também, quando comparado à lamivudina (100mg/dia) em considerável melhora histológica (70\% vs 61\%), redução do DNA-VHB sérico $\left(-5,0\right.$ vs $\left.-4,5 \log _{10}\right)$ e indetectabilidade deste teste na grande maioria dos casos ( $90 \%$ vs $72 \%$ ); normalização da ALT ocorreu em cerca de 80\% dos doentes tratados, embora não tenha havido diferença na melhora da fibrose, à biópsia hepática, quando comparado com a lamivudina. Nenhuma mutação de resistência foi detectada nas semanas 48 e 96 de tratamento, em ambos os grupos de pacientes AgHbe positivos e

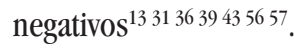

Entecavir também mostrou-se ativo em pacientes portadores do VHB resistentes à lamivudina; em estudo que incluiu 181 pacientes com cepas VHB com mutações no lócus YMDD da polimerase viral, diferentes doses $(0,1 ; 0,5$; e $1 \mathrm{mg} /$ dia) de entecavir foram testadas e comparadas com a lamivudina. Na semana 24 do tratamento o percentual de pacientes com DNA-VHB indetectável foi 19\% com 0,1mg/dia, $53 \% \mathrm{com} 0,5 \mathrm{mg} / \mathrm{dia}$ e $79 \% \mathrm{com} 1 \mathrm{mg} / \mathrm{dia}$ comparado com $13 \%$ no grupo recebendo lamivudina. Portanto, $1 \mathrm{mg} / \mathrm{dia}$ parece ser, como referido, a dose ideal para tratar cepas resistentes a lamivudina. Ao contrário do observado em cepas sensíveis, resistência ao entecavir (9\%) tem sido observada em pacientes com mutantes resistentes a lamivudina ( mutações nas posições 184, 202 e 250$)^{4283136394356}$

Emtricitabina: essa droga é um análogo de nucleosídeo com atividade antiviral contra $o$ VHB e o HIV. Sua estrutura é muito semelhante à da lamivudina e sua atividade antiviral contra 0 VHB já foi confirmada em vários trabalhos da literatura. Em um estudo randomizado duplo-cego, envolvendo 98 asiáticos (77 AgHbe positivos e 21 AgHbe negativos), administrou-se emtricitabina diária por 48 semanas, em três doses diferentes: 25, 100 e $200 \mathrm{mg} /$ dia e ao final do tratamento observou-se que da queda na carga viral de $2,6 \log _{10}, 3,1 \log _{10}$ e $2,9 \log _{10}$ cópias/ml para as 3 doses respectivamente; carga viral indetectável foi observada em 38, 42 e $61 \%$ para as 3 doses, respectivamente. A perda do AgHbe foi observada em 32 a $50 \%$ dos pacientes, dependendo da dose utillizada. Sua eficácia foi também notável na hepatite crônica AgHbe negativa. A dose preconizada, portanto, é de $200 \mathrm{mg} / \mathrm{dia}$, em única tomada por via oral. Resistência à esta droga tem sido observada durante 0 tratamento; após 48 semanas de terapia, $12 \%$ dos pacientes tratados com 100mg diários da droga e 6\% dos tratados com $200 \mathrm{mg} /$ dia desenvolveram resistência. 0 papel dessa medicação como monoterapia, à semelhança da lamivudina, parece ser limitado devido ao alto risco de desenvolvimento de resistência a longo prazo. Efeitos colaterais da droga são escassos e de pequena magnitude ${ }^{2831343643}$.

Telbivudina: esse análogo nucleosídico apresenta, como veremos uma atividade potente, seletiva e específica sobre os hepaDNAvírus, bloqueando rapidamente a replicação viral. Os primeiros estudos já mostraram que esse medicamento não tem toxicidade mitocondrial, nem efeitos mutagênicos. Foi recentemente aprovada para tratamento da infecção crônica pelo VHB. A dose utilizada é de $600 \mathrm{mg}$, via oral, por dia. 0 estudo GLOBE, multicêntrico, envolvendo 1367 pacientes com hepatite crônica $\mathrm{B}$, comparou a telbivudina com a lamivudina no tratamento dessa virose e os dados obtidos na $48^{\circ}$ semana de terapia já se encontram disponíveis; todos os pacientes tratados apresentavam DNA-VHB sérico $>6 \log _{10}$ cópias/ml, ALT $1.3-10 \mathrm{x}$ o valor normal e doença hepática compensada. Após 48 semanas observou-se nos pacientes do braço telbivudine AgHbe positivos, soroconversão AgHbe $\rightarrow$ anti-Hbe em 38\%, normalização da ALT em $90 \%$ e negativação do DNA-VHB sérico em $95 \%$ dos pacientes. Nos AgHbe negativos, a ALT normalizou-se em 79\% e o DNA-VHB sérico negativou-se em $96 \%$ dos pacientes; resistência durante 0 tratamento já foi documentada, à semelhança do que se observa durante $o$ tratamento com lamivudina (durante o primeiro ano, 13\% em AgHbe positivos e 39\% em AgHbe negativos) ${ }^{2843}$.

Outro estudo comparou durante 1 ano, a telbivudina com 0 adefovir em 133 adultos AgHbe positivos (44 tratados com telbuvidina e 89 com adefovir); todos tinham DNA-VHB séricos $>6 \log _{10}$ cópias/ml, ALT elevada e doença compensada. Na $24^{\mathrm{a}}$ semana de tratamento observou-se queda considerável do DNA-VHB no soro em ambos os braços $\left(6.37 \log _{10}\right.$ no braço telbivudina e $5.11 \log _{10}$ no adefovir), normalização da ALT em $60 \%$ dos casos em ambos os braços do estudo e soroconversão AgHbe $\rightarrow$ anti-Hbe em $16 \%$ dos tratados com telbivudina e 10\% dos tratados com adefovir ${ }^{73}$.

Quando se utiliza esta droga por períodos mais prolongados, os resultados são excelentes; após 76 semanas de uso contínuo desse nucleosídeo em 163 pacientes AgHbe positivos, observouse negativação do DNA-VHB sérico em $70 \%$ dos pacientes, normalização da ALT em 78\% e perda do AgHbe em $40 \%$ dos casos tratados; na semana 52 da terapia, 3\% dos pacientes desenvolveram resistência. Em todos os estudos efeitos colaterais foram raros e discretos; portanto esse medicamento parece promissor no tratamento da hepatite crônica $\mathrm{B}^{28}$.

Tenofovir disoproxil: esse análogo nucleotídico está hoje aprovado apenas para tratamento das infecções pelo HIV, mas apresenta excelente atividade sobre o VHB, seja nas cepas selvagens ou resistentes a outras drogas (lamivudina, adefovir). Poucos estudos avaliaram a ação dessa medicação em pacientes monoinfectados (não HIV positivos), portanto poucos dados encontram-se disponíveis para avaliaçã̃o. Um trabalho recente avaliou a ação dessa droga em pacientes com hepatite crônica B AgHbe positivos resistentes a lamivudina e comparou-se sua atividade com 0 adefovir dipivoxil; 44 pacientes foram tratados com tenofovir e 65 com adefovir. Os critérios de inclusão foram os clássicos empregados em outros estudos; ambas aos 6 meses, mostraram atividade substancial sobre o DNA-VHB sérico (tenofovir - queda > $3 \log _{10}$ em $63 \%$ dos casos), normalização da ALT em 60\% dos casos (com ambas as drogas) e soroconversão em poucos casos ( $4 \%$ no tenofovir e $7 \%$ no adefovir); mais dados sobre a atividade desse medicamento na hepatite B serão discutidos no tópico co-infecção VHB/HIV 2831 .

Clevudine: essa droga é um análogo pirimidínico com marcada atividade in vitro contra $0 \mathrm{VHB}$, mas não contra 0 
HIV; estudos in vitro sugerem que é ativo contra cepas do VHB resistentes à lamivudina. A droga é segura, sem efeitos adversos apreciáveis. A atividade antiviral, resposta bioquímica e sorológica foram mostradas em pacientes recebendo clevudine na dose de $30 \mathrm{mg} /$ dia por 24 semanas seguido por uma dose mais baixa de $10 \mathrm{mg} /$ dia por mais 24 semanas como terapia de manutenção e seguimento posterior por um período de 12 semanas; resultados preliminares dos primeiros 31 pacientes (25 AgHbe positivos, 6 AgHbe negativos) que completaram o tratamento mostraram que na semana $24,94 \%$ dos pacientes e na semana $48,87 \%$ deles tinham DNA-VHB sérico < 4.700 cópias/ml; ainda na semana 48, $71 \%$ dos doentes tratados (68\% nos AgHbe positivos, 83\% nos AgHbe negativos) tinham carga viral indetectável (<300 cópias/ml por PCR); também na semana 48, 97\% dos pacientes tinham ALT normal e $20 \%$ dos AgHbe positivos soroconverteram à anti-Hbe. Portanto, essa droga é promissora no tratamento da infecção crônica pelo VHB, demonstrando significativa supressão viral e melhora bioquímica após 48 semanas de tratamento ${ }^{10} 284243$.

Pradefovir: esse medicamento é uma pró-droga ativa do adefovir. Estudos animais mostram que após a sua administração, existem altos níveis da droga ativa no fígado e nenhuma concentração renal, evitando, portanto, a nefrotoxicidade do adefovir. É rapidamente absorvida por via oral, possui poucos efeitos adversos e na dose de $60 \mathrm{mg} /$ dia reduz a carga viral em cerca $3 \log _{10}$ num curto período de 28 dias. Estudos de fase II estão em andamento avaliando a eficácia dessa droga em portadores do $\mathrm{VHB}^{28}$.

Terapia combinada no tratamento da hepatite $B$ crônica. Alguns trabalhos sugerem que existe algum efeito, aditivo da terapia combinada de intérferon $\alpha$ e lamivudina, embora outros estudos necessitem confirmar essas observações. Dados recentes mostram que a combinação de PEG-IFN $\alpha$ 2a e lamivudina em pacientes AgHbe $\odot$, durante 1 ano, não mostrou grande benefício em relação à monoterapia com PEG-IFNo ou lamivudina ${ }^{42}$. A combinação de adefovir e emtricitabina comparada ao adefovir isolado demonstrou em 30 pacientes AgHbe positivos tratados, que a combinação alcançou maior supressão da carga viral após 48 semanas de terapia $\left(5,44 \log _{10} \times 3,40 \log _{10}\right)$. Em outro estudo similar, comparando lamivudina mais adefovir com lamivudina isolada, nenhum benefício foi alcançado com a combinação. A combinação de drogas pode prevenir a resistência do vírus B às medicações e representa o maior benefício dessa estratégia, embora maiores estudos sejam necessários para confirmar esse conceito $^{23283031333639}$.

Durabilidade da resposta aos antivirais na hepatite B crônica. A durabilidade da perda do AgHbe induzida pelo tratamento com intérferon $\alpha$ parece ser de 80 a 90\% após 4 a 8 anos de seguimento pós terapia. Nos casos tratados com lamivudina que soroconverteram durante o tratamento, a resposta se manteve em $77 \%$ dos casos após seguimento de 37 meses; hoje considera-se que a soroconversão é preferível em relação à perda do AgHbe isolada e todos os pacientes devem manter o tratamento por pelo menos 6 meses após a detecção da soroconversão para aumentar a durabilidade da resposta ${ }^{17}$. Com o adefovir, a manutenção da resposta ao tratamento tem sido estimada em
91\% após mais de um ano sem medicação e com o entecavir foi de $82 \%$ após 24 semanas sem tratamento. No geral, é prudente manter a terapia por um período maior, com qualquer das drogas, após a soroconversão AgHbe-anti-Hbe, para conservar a resposta obtida com a medicação ${ }^{283136}$.

Tratamentos dos pacientes cirróticos AgHbs $\oplus$. Antes do advento da terapia antiviral, pacientes com cirrose pelo VHB apresentavam sobrevida de 5 anos, de cerca de $84 \%$ para os compensados (Child A) e de $15-35 \%$ para os descompensados (Child C); aqueles que desenvolviam soroconversão AgHbe $\rightarrow$ anti-Hbe mostravam $97 \%$ de sobrevida aos 5 anos e os que não desenvolviam apenas $72 \%$ estavam vivos após este período, mostrando, portanto, que a replicação viral tem papel preponderante no curso evolutivo da doença $\mathrm{a}^{20}{ }^{50}$. Atualmente, recomenda-se que cirróticos compensados e com níveis de DNA-VHB $<2.000 \mathrm{UI} / \mathrm{ml}$ (ou $<10^{4}$ cópias $/ \mathrm{ml}$ ) sejam apenas monitorados periodicamente ou que sejam tratados com adefovir ou entecavir; essas drogas são bem toleradas e podem, como já vimos, serem utilizadas por longos períodos, com baixo desenvolvimento de resistência; naqueles com DNA-VHB sérico > 2.000UI/ml, essas drogas (entecavir ou adefovir) estão indicadas como opções de primeira linha para tratamento; os intérferons (qualquer formulação) estão contra-indicados nesses doentes porque podem levar à descompensação da hepatopatia. Lamivudina não deve ser administrada isoladamente porque em tratamento de longa duração, existe um alto risco de desenvolvimento de resistência, com surgimento de sinais e sintomas de descompensação clínica (icterícia, ascite, etc) e elevações, por vezes, consideráveis, das aminotransferases. Combinações de lamivudina com adefovir (ou entecavir) teria 0 benefício teórico de reduzir o desenvolvimento de resistência a uma ou a ambas as drogas 202123283135363950.

Todos os cirróticos descompensados, independentes do seus níveis de DNA-VHB séricos, devem ser considerados para tratamento. Combinações de drogas análogos de nucleosídeos/ nucleotídeos devem ser as preferidas (lamivudina com adefovir ou possivelmente, entecavir), para iniciar o tratamento e após a compensação do paciente, muitos podem ser, inclusive, removidos da lista de transplantes. Como já referido, a terapia combinado pode retardar ou diminuir o desenvolvimento de resistência. A duração do tratamento nos cirróticos ainda é indefinido, mas deve ser mantido até que os níveis de DNA-VHB séricos se tornem negativos ou haja perda do AgHbs. Pacientes sob terapia antiviral devem ser monitorados a cada 3 a 6 meses, para avaliação da resposta ao medicamento e para detecção eventual de hepatocarcinoma (com ultrassonografia abdominal e dosagem da $\alpha_{1}$ fetoproteína sérica), que poderá surgir mesmo nos indivíduos com baixa replicação viral 2021262831353639 . A Tabela 4 mostra a conduta atual no tratamento de pacientes cirróticos $\mathrm{AgHbs} \oplus$.

Conduta terapêutica nos portadores de hepatite $B$ imunodeprimidos e em mulheres grávidas. Reativação da replicação do VHB com aumento do DNA-VHB sérico e dos níveis de ALT tem sido observados em 20 a 50\% dos portadores de AgHbs sob quimioterapia antineoplásica ou outra terapia imunodepressora. 0 quadro de reativação pode ser assintomático, 
Tabela 4 - Recomendações para tratamento de pacientes cirróticos $\mathrm{VHB} \oplus *$ *.

\begin{tabular}{cccc}
\hline AgHbe & DNA-VHB ${ }^{* * *}(\mathrm{UI} / \mathrm{ml})$ & Cirrose & Tratamento (longo prazo) \\
\hline$\oplus / \odot$ & $<2000$ & compensada & opcional; adefovir ou entecavir \\
$\oplus / \odot$ & $\geq 2000$ & compensada & adefovir ou entecavir \\
& & & ou combinação de drogas \\
$\oplus / \odot$ & $<200$ ou $\geq 200$ & descompensada & combinação de drogas
\end{tabular}

(lamivudina + adefovir ou entecavir); transplante

\footnotetext{
* adaptado de Keefe et al, 2006

** $1 \mathrm{UI}=5,6$ cópias
}

mas icterícia e descompensação hepática podem ser observados em alguns pacientes. Diversos estudos mostram que a terapia profilática com lamivudina pode reduzir os episódios de reativação, sua gravidade e letalidade. 0 tratamento deve ser administrado no início da terapia imunodepressora e mantido por um período mínimo de 3 meses. Terapêutica a longo prazo, em transplantados de órgãos sólidos sob imunodepressão crônica, é ainda, objeto de discussão. Outras drogas, além da lamivudina, tais como o adefovir ou entecavir também podem ser utilizadas. Como a terapia é de curta duração, o problema da resistência do VHB às drogas antivirais não tem maior relevância. É importante ressaltar que mesmo aqueles pacientes que apresentam apenas o marcador anti-Hbc isolado, devem ser tratados profilaticamente para evitar reativações ${ }^{9313658}$.

Em mulheres grávidas portadoras de hepatite B crônica, todas as 3 drogas, lamivudina, entecavir e adefovir podem ser utilizadas com segurança, sendo a experiência maior com a lamivudina. A decisão de tratar a mulher grávida VHB positiva vai depender do estágio de sua doença hepática e dos benefícios ou malefícios que a terapêutica poderá trazer ao concepto. Em doença leve ou compensada, é prudente, aguardar o término da gestação e depois iniciar a terapia antiviral. 0 tratamento durante o terceiro trimestre da gestação pode prevenir a transmissão materno-fetal mas este fato não deve impedir o uso da profilaxia perinatal ao recém-nascido com imunoglobulina e vacinação anti-VHB ${ }^{2831}$.

Manuseio dos pacientes com resistência antiviral. 0 desenvolvimento de resistência a qualquer das drogas hoje utilizadas no tratamento da hepatite B crônica pode ser detectada através da elevação dos níveis de DNA-VHB sérico, acima de $1 \log _{10}$, tomando-se como base o nível mais baixo alcançado durante 0 tratamento, acompanhado de elevação da ALT, reversão da melhoria histológica inicial e, em alguns casos, de quadro clínico grave de icterícia e descompensação hepática. A resistência denominada genotípica pode ser comprovada pela detecção de mutações na polimerase do VHB através do seqüenciamento direto dos produtos do PCR. Nos pacientes que desenvolvem resistência a lamivudina (até $70 \%$ após 5 anos de uso da droga), deve-se adicionar 0 adefovir e manter as duas drogas por pelo menos 3 meses ou trocar a lamivudina pelo entecavir; no futuro, é possível que se recomende adicionar o tenofovir à lamivudina ou substituíla pela combinação de tenofovir e emtricitabina, combinação com baixo índice de desenvolvimento de resistência a longo prazo; quando ocorre o aparecimento de resistência a adefovir (29\% após 5 anos de tratamento), recomenda-se adicionar a lamivudina ou trocar pelo entecavir ou pela combinação de tenofovir e emtricitabina. Nos raros casos de detecção de resistência ao entecavir (9\% após 2 anos de uso em pacientes portadores de VHB resistentes à lamivudina) recomenda-se adicionar ou trocar a droga pelo adefovir ou tenofovir ${ }^{28} 31384653$.

Algumas medidas tem sido adotadas para prevenir 0 aparecimento de resistência do VHB aos antivirais: a) usar agentes com alta barreira genética para resistência (entecavir); b) trocar a terapia inicial quando não há resposta virológica nos primeiros 6 meses de uso da medicação; c) evitar monoterapia seqüencial e d) usar combinações de drogas quando possível; esta última recomendação provavelmente se tornará o ponto fundamental na terapia da hepatite crônica $\mathrm{B}^{2831384653}$.

A Tabela 5 mostra as recomendações atuais para tratamento da hepatite B crônica AgHbe $\oplus / \odot$ com base na carga viral e nos níveis de ALT séricos.

Tabela 5 - Recomendações para o tratamento da bepatite crônica B AgHbe $\oplus / \odot$ *

\begin{tabular}{llll}
\hline AgHbe & DNA-VHB (UI/ml) & ALT & Tratamento \\
\hline$\oplus$ & $<20.000$ & $\mathrm{~N}$ & nenhum (monitorar cada 6-12m) \\
$\oplus$ & $\geq 20.000$ & $\mathrm{~N}$ & $\begin{array}{l}\text { Imunotolerância; considerar biópsia hepática; } \\
\text { tratar se ANI } \uparrow\end{array}$ \\
$\oplus$ & $\geq 20.000$ & $\uparrow$ & $\begin{array}{l}\text { PEG-INF } \alpha, \text { adefovir, entecavir, lamivudina*** } \\
\text { biópsia opcional) }\end{array}$ \\
$\odot$ & $<2.000$ & $\mathrm{~N}$ & portador inativo; não tratar; monitorar \\
$\odot$ & $\geq 2.000$ & $\mathrm{~N}$ & biópsia hepática indicada; tratar se ANI $\uparrow$ \\
$\odot$ & $\geq 2.000$ & $\uparrow$ & entecavir, adefovir, PEG-INF ${ }^{* * * *}$ \\
& & & terapia por longo prazo com drogas orais \\
\hline
\end{tabular}

* adaptado de Keefe et al, 2006

*** ocorrência considerável de resistência

**** tratamento por um ano

个: elevada $\uparrow$ índice de resposta. N: normal

ANI: atividade necro-inflamatória. PEG-INF: interferon peguilado

\section{CO-INFECÇÃO VÍRUS DA IMUNODEFICIÊNCIA HUMANAV VÍRUS DA HEPATITE B}

A co-infecção do vírus da hepatite $\mathrm{B}$ com o vírus da imunodeficiência humana ocorre com prevalência entre 5 e $10 \%$ e, diferentemente dos monoinfectados com VHB, os co-infectados apresentam menor chance de cura espontânea da hepatite B aguda. (95\% x 77\%, respectivamente). Alguns estudos iniciais reportaram menor progressão da doença hepática nestes pacientes, apesar da persistência do AgHbs e até mesmo do AgHBe, atribuindo tal resultado à menor agressão hepática resultante da má resposta imune induzida pelo HIV. Tais achados, entretanto, não se comprovaram em grandes estudos multicentros, que demonstraram o maior risco de morte por doença hepática nestes indivíduos, principalmente entre aqueles com baixos níveis de linfócitos T CD4 ( $<100$ células/ $\left.\mathrm{mm}^{3}\right)$ e etilistas crônicos. Esse mesmo resultado também foi encontrado pelo grupo EUROSIDA, em 2005, que avaliou não só a progressão da doença hepática, mas também o efeito da presença do AgHBs na progressão da Aids, na mortalidade e na resposta à HAART. Os co-infectados, 
portanto, apresentam maior risco de cronicidade, altos títulos de DNA-VHB sérico e evoluem com doença hepática rapidamente progressiva, apesar dos baixos níveis das aminotransferases. Além disso, a morbidade/mortalidade associada ao hepatocarcinoma é mais freqüentemente encontrada na co-infecção HIV/VHB, sendo responsável por até $50 \%$ dos óbitos relacionados à doença hepática neste grupo de pacientes, significativamente maior do que na co-infecção HIV/VHC 115454951526061 .

A terapia anti-retroviral potente pode modificar a história natural da hepatite $\mathrm{B}$, entre os co-infectados, sob dois aspectos: primeiro, através da recuperação imune, que, teoricamente, evitaria a rápida progressão da hepatopatia como descrita acima, embora, por outro lado, apesar da redução na incidência de eventos definidores de AIDS, a mortalidade atribuída à doença hepática terminal vem superando as outras causas de morte. Segundo, o risco de toxicidade hepática oriunda da terapia HAART está aumentado nos portadores de hepatites virais, além do que a recuperação imune pode acelerar o dano hepático nos co-infectados, através dos flares, principalmente em pacientes com altos níveis basais de ALT e naqueles com fibrose hepática mais avançada. Tais exacerbações podem, ainda, resultarem da emergência de cepas resistentes à lamivudina (mutação YMDD), durante terapia combinada ${ }^{111544455152596061}$.

Diante do discutido, para o tratamento da hepatite B, em pacientes co-infectados, deve-se levar em conta a indicação ou não de se tratar conjuntamente as duas infecções. A prioridade é o controle da infecção pelo HIV, uma vez que o sucesso terapêutico na doença pelo VHB é diretamente proporcional ao número de linfócitos T CD4 e, além disso, a inclusão de drogas ativas, anti-VHB, no esquema HAART torna-se fundamental para 0 alcance desse sucesso. Para evitar o surgimento de resistência e, conseqüentemente, os flares, recomenda-se terapia combinada, utilizando lamivudina com tenofovir no esquema anti-retroviral inicial para todos os co-infectados com hepatite B ativa, principalmente para os cirróticos.

Interferon $\alpha$ foi a primeira droga utilizada para tratamento da hepatite crônica $B$, porém seus efeitos colaterais e a baixa resposta limitam seu uso, particularmente em pacientes co-infectados. Tanto sua apresentação convencional quanto a peguilada têm indicações bem estabelecidas, ou seja, para pacientes ainda não candidatos à HAART, com altos níveis de ALT, AgHbe positivos e baixos títulos do DNA-VHB sérico. Nestes casos, a soroconversão AgHbe/anti-Hbe pode ser alcançada em 15\% dos pacientes e DNA-VHB indetectável, em $27 \%$, após 3 anos de seguimento. Não é recomendado utilizar-se essa citocina em doentes com cirrose estabelecida uma vez que os flares, durante o tratamento, são mais comuns entre os co-infectados ${ }^{16}$.

A lamivudina permaneceu, por muito tempo, como única opção de droga oral com atividade anti-VHB e anti-HIV. A dose de 300mg/dia utilizada no tratamento do HIV é superior à necessária para inibir a replicação do VHB (100mg/dia), que ocorre em cerca de $86 \%$ dos pacientes co-infectados nos primeiros 12 meses, mas com altos índices de resistência, chegando a 94\% após 4 anos, indicando que a seleção de mutações ocorre mais rapidamente do que nos monoinfectados pelo VHB. A soroconversão AgHbe/anti-Hbe, entretanto, só ocorre em uma minoria dos casos, embora o benefício histológico e a redução dos eventos de descompensação hepática entre os cirróticos são notórios e significativos. Diante destes e de outros resultados, o uso da lamivudina como monoterapia para tratamento da hepatite B em co-infectados deve ser desencorajada ${ }^{182745}$.

A emtricitabina (FTC), que não está incluída entre as drogas utilizadas para o tratamento do HIV no Brasil, apresenta estrutura e eficácia semelhantes à lamivudina tanto na sua atividade antiHIV quanto anti-VHB, inclusive com o potencial de desenvolver a mutação YMDD, porém mais lentamente.

Mais recentemente, o tenofovir, um análogo de nucleotídeo, embora não aprovado para tratamento da hepatite B em monoinfectados, tem demonstrado excelente atividade antiVHB, inclusive na presença de resistência à lamivudina. Vários estudos confirmaram sua eficácia também em co-infectados. De 52 pacientes avaliados randomicamente recebendo tenofovir ou adefovir, associado ao esquema HAART, a queda do DNA-VHB sérico, na semana 48 , foi de $-4,4 \log _{10}$ para o grupo do tenofovir e -3,21 $\log _{10}$ para o adefovir ${ }^{32}$. Em outra série de 40 indivíduos co-infectados recebendo tenofovir, 25 (63\%) tiveram o DNA-VHB sérico indetectável na semana 48 e soroconversão AgHbe/anti-Hbe ocorreu em 6 (15\%), entre as semanas 36 e 96 de tratamento.

A carga viral basal e a presença do AgHBe foram os únicos fatores associados à resposta virológica precoce ao tenofovir, como demonstrado em estudo preliminar e prospectivo de 28 pacientes co-infectados. Em análise multivariada, o genótipo do vírus $B$, o grau de fibrose, a presença da mutação YMDD e a positividade para VHC ou HIV não influenciaram o resultado final desta série(16). Mutações no gene da polimerase, como a rtA194T, associadas à resistência ao tenofovir, foram demonstradas em pacientes com persistência do DNA-VHB sérico, após 24 semanas de tratamento com tenofovir e lamivudina. 0 impacto destes achados precisa ser melhor avaliado $0^{32445} 4854$.

0 uso do adefovir na dose oral de $10 \mathrm{mg} /$ dia tem boa ação sobre o VHB, com AgHbe positivo ou negativo, inclusive na presença da mutação YMDD. Sua indicação está limitada aos monoinfectados, dada a grande potência do tenofovir (que é derivado do adefovir) sobre os dois vírus, inclusive mostrando-se eficaz mesmo nos casos previamente falhados com adefovir.

Os co-infectados que ainda não utilizam a terapia HAART e aqueles que não responderam ou demonstram contra-indicações ao uso do intérferon $\alpha$, poderão se beneficiar com o uso do adefovir, já que ainda não se tem demonstrado mutações de resistência nos infectados pelo HIV, induzidas por este análogo de nucleotídeo. Quando associado à lamivudina em 30 pacientes co-infectados e com a mutação YMDD, somente $25 \%$ alcançaram níveis indetectáveis do DNA-VHB e 45\% atingiram < 1.000 cópias/ $\mathrm{ml}$, após 3 anos de seguimento. Estes resultados contrastam com o observado em indivíduos monoinfectados pelo VHB, resistentes à lamivudina, cuja falha com uso do adefovir foi observada em apenas $18 \%$ dos casos. Tais achados sugerem o benefício da associação do adefovir à lamivudina quando se detecta a presença da mutação YMDD 404555 . 
O entecavir, outro análogo de nucleosídeo liberado para tratamento da hepatite crônica $B$, apresenta excelente atividade anti-VHB tanto para AgHBe positivos quanto negativos, virgens de tratamento ou resistentes à lamivudina. Neste último caso, na presença da mutação YMDD, menos de $2 \%$ dos que usaram entecavir experimentaram recaída na semana 48 , associada ao acúmulo de mutações de resistência na polimerase do VHB. Em 6\% dos pacientes, entretanto, já se detectava tais mutações no período pré-tratamento com entecavir. Estudos preliminares também apontam a eficácia desta droga em pacientes co-infectados com HIV, podendo ser uma ótima opção para pacientes ainda sem indicação para HAART. A maior freqüência de resistência à lamivudina neste grupo, contudo, pode ser um fator limitante ao seu uso a longo prazo, dados que ainda precisam ser avaliados. $\mathrm{Na}$ co-infecção, a dose de $1 \mathrm{mg} /$ dia é a recomendada para início do tratamento, diferentemente do indicado para monoinfectados, $0,5 \mathrm{mg} / \mathrm{dia}^{12} 44546$.

Apesar dos avanços recentes no conhecimento da hepatite B, estratégias para seu tratamento precisam, ainda, ser estabelecidas, principalmente na co-infecção com HIV. Para estes, o esquema terapêutico adequado, com baixa toxicidade e sem interação com o esquema HAART, que possa induzir resposta duradoura e menor risco de resistência, precisa ser melhor definido. Pacientes que ainda não requerem HAART, o uso do interferon $\alpha$ ou do entecavir, no momento, parece o mais apropriado. Para o tratamento concomitante de ambas as infecções, a combinação de tenofovir e lamivudina é o recomendado ${ }^{45} 484$.

Questões quanto ao tratamento de pacientes com ALT normal e carga viral do VHB elevada ou, daqueles com baixos níveis de ALT (menos de 2 vezes o limite normal, por exemplo) e com DNA-VHB sérico em baixos títulos, ainda estão sem resposta. A biópsia deve ser considerada para orientar o tratamento nestes $\operatorname{casos}^{45}$.

0 algoritmo da Figura 2 e a Tabela 6 a seguir, resumem os comentários do texto quanto às condutas e indicações de tratamento da hepatite B em pacientes co-infectados com HIV $^{1}$.

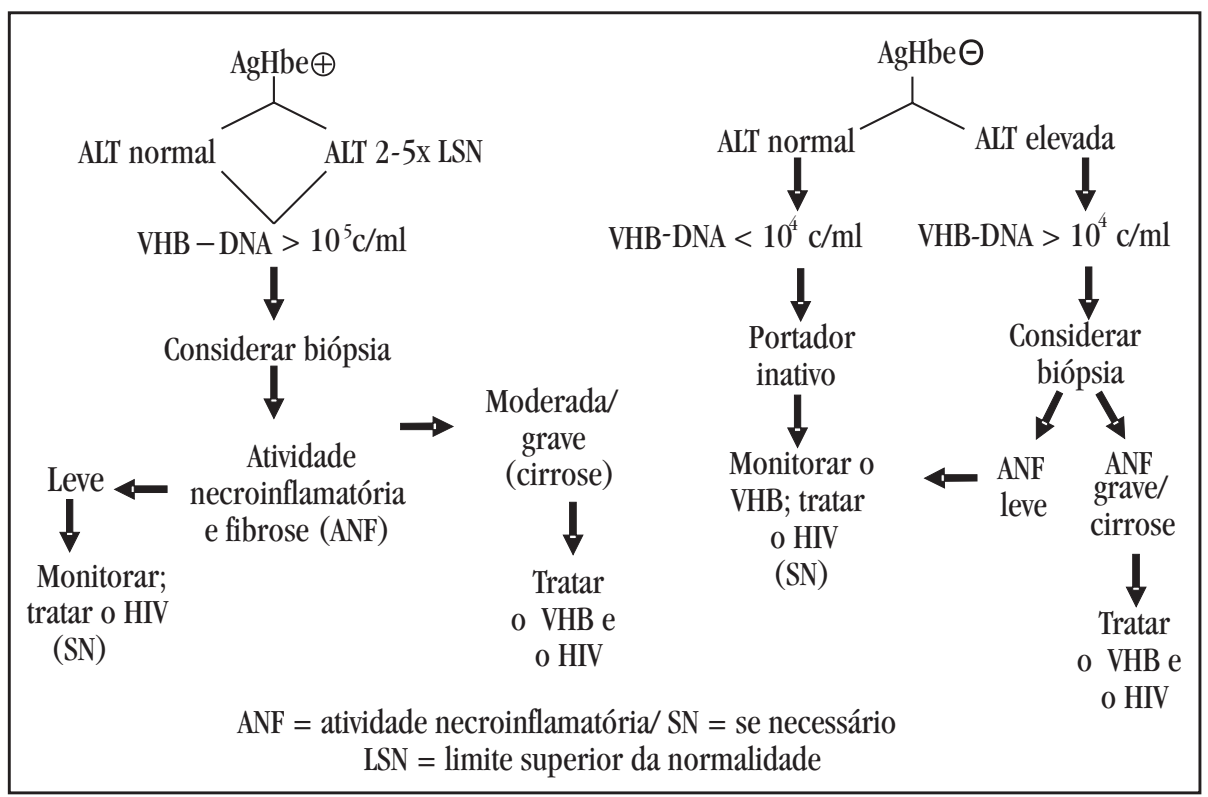

Figura 2 - Algoritmo para manuseio da co-infecção vírus da imunodeficiência humana/vírus da bepatite B.

Tabela 6 - Tratamento da bepatite crônica B em pacientes HIV/VHB*.

\begin{tabular}{|c|c|c|c|}
\hline Indicação para terapia antiviral & AgHbe/PCR & Regime preferido & Evitar \\
\hline \multirow[t]{2}{*}{ Somente VHB (cepa selvagem/mutante pré-core) } & a) $\mathrm{AgHbe} \oplus$ & IFN (PEG), ADF, ETV & LAM, FTC,TDF \\
\hline & b) AgHbe $\odot$ & ADF, ETV & LAM, FTC, TDF \\
\hline \multirow[t]{3}{*}{ Somente HIV } & AgHbe $\oplus / \odot+$ & & \\
\hline & a) DNA-VHB $<10^{4} \mathrm{cop} / \mathrm{ml}$ & monitorar & \\
\hline & b) DNA-VHB $>10^{4}$ ou $5 \mathrm{cop} / \mathrm{ml}$ & HAART c/ TDF + LAM ou FTC *** & monoterapia c/ LAM ou FTC \\
\hline HIV e VHB (cepa selvagem/mutante pré-core) & AgHbe $\oplus$ ou $\odot$ & HAART c/ TDF + LAM ou FTC & monoterapia c/ LAM ou FTC \\
\hline VHB resistente LAM (YMDD) & AgHbe $\oplus$ ou $\odot$ & HAART c/ TDF & Descontinuar LAM \\
\hline
\end{tabular}




\section{REFERÊNCIAS}

1. Benhamou, Y. Treatment algorithm for chronic hepatitis B in HIV-infected patients. Journal of Hepatology 44:90-94, 2006.

2. Bruix J, Sherman M. Management of hepatocellular carcinoma. Hepatology 42:1208-1236, 2005.

3. Buti M, Cotrina M, Jardi R. Two years of lamivudine therapy in anti-Hbe positive patients with chronic hepatitis B. Journal of Viral Hepatitis 11:432-438, 2004.

4. Chan HLY, Lai CL, Cho M, Heathcote J. A randomized trial of telbivudine (LDT) vs adefovir for HbeAg positive chronic hepatitis B results of the primary week 24 analysis. Journal of Hepatology 44:524-525, 2006.

5. Chang T, Gish R, Deman R. A comparison of entecavir and lamivudine for HbeAgpositive chronic hepatitis B. The New England Journal of Medicine 354:10011010, 2006.

6. Chang TT, Gish RG, Hadziyannis SJ, Cianciara J, Rizzetto M, Schiff ER; BEHOLD Study Group. A dose ranging study of the efficacy and tolerability of entecavir in lamivudinerefractory chronic hepatitis B. Gastroenterology 129:1198-1209, 2005.

7. Chu CJ, Hussain M, Lok ASE. Quantitative serum HBV DNA levels during different stages of chronic hepatitis B infection. Hepatology 36:1408-1415, 2002.

8. Chu CJ, Lok AS. Clinical significance of hepatitis B virus genotypes. Hepatology 35:1274-1276, 2002

9. Cinjeevaran HS, Lok AS. Occult hepatitis B virus infection: a hidden menace? Hepatology 34:204-206, 2001.

10. Chung YH, Lee KS, Kim JH, Ryn SH, Paik SW. One year treatment with clevudine demonstrated significant viral suppression and biochemical improvement in chronic hepatitis B. Journal of Hepatology 44:524-525, 2006.

11. Colin JF, Cazals-Hatem D, Loriot MA. Influence of human immunodeficiency virus infection on chronic hepatitis B in homossexual men. Hepatology 29: 1306-1310, 1999 .

12. Colonno R, Rose R, Baldick CJ.. Week- 48 resistance surveillance of HIV/HBV coinfected patients treated with entecavir in study AI463038. In Program and Abstracts of the $13^{\text {th }}$ Conference on Retroviruses and Opportunistic Infections; 2006; Denver, Colorado, USA.

13. Colonno RJ, Rose R, Baldick CJ, Levine S, Yu CF, Walsh A, Fang J, Hsu M, Mazzuco C, Eggers B, Zhang S, Plym M, Klesczewski K, Tenney DJ. Entecavir resistance is rare in nucleoside naïve patients with hepatitis B. Hepatology 44:1656-1665, 2006.

14. Dando TM, Plosker GL. Adefovir dipivoxil: a review of its use in chronic hepatitis B. Drugs 63:2215-2234, 2003.

15. Den Brinker M, Wit FW, Wertheim-van Dillen PM. Hepatitis B and C virus coinfection and the risk for hepatotoxicity of highly active antiretroviral therapy in HIV-1 infection. AIDS 14: 2895-2902, 2000.

16. Dienstag JL, Ciancara J, Karayalcin S. Durability of serologic response after lamivudine treatment of chronic hepatitis. B. Hepatology 37:748-755, 2003.

17. Di Martino V, Thevenot T, Colin JF. Influence of HIV infection on the response to interferon therapy and the long-tern outcome of chronic hepatitis $B$. Gastroenterology 123:1812-1822, 2002.

18. Dore GJ, Cooper DA, Barrett C. Dual efficacy of lamivudine treatment HIV-hepatitis B coinfected persons in a randomized, controlled study (CAESAR). Journal of Infections Diseases 180:607-613, 1999.

19. Ferreira MS. Diagnóstico e tratamento da hepatite B. Revista da Sociedade Brasileira de Medicina Tropical 33:389-400, 2000.

20. Fontana RJ. Management of patients with decompensated HBV cirrhosis. Seminars in Liver Diseases 23:89-100, 2003

21. Fung SK, Lok ASF. Management of patients with hepatitis B virus-induced cirrhosis. Journal of Hepatology 42:54-64, 2005.

22. Ganem D, Prince AM. Hepatitis B vírus infection - natural history and clinical consequences. The New England Journal of Medicine 350:1118-1129, 2004.

23. Ghany M, Lutchman G, Kleiner D. Lamivudine and adefovir versus adefovir alone for HbeAg-positive chronic hepatitis B. Hepatology 42:591-592, 2005.

24. Guan R, Lai CL, Liaw YF. Efficacy and safety of 5 years lamivudine treatment of chinese patients with chronic hepatitis B. Journal Gastroenterology and Hepatology 16:A60-A61, 2001.
25. Hadziyannis SJ, Tassopoulos NC, Heathcote EJ. Long-term therapy with adefovir dipivoxil for HbeAg-negative chronic hepatitis B. The New England Journal of Medicine 352:2673-2681, 2005.

26. Hayashi PH, DiBisceglie AM. The progression of hepatitis B and C infections to chronic liver diseases and hepatocelular carcinoma: presentation, diagnosis, screening, prevention and treatment of hepatocellular carcinoma. Infections Disease Clinics of North América 20:1-25, 2006.

27. Hoff J, Bani-Sadr F, Gassin M, Faffi F. Evaluation of chronic hepatitis B virus infection in co-infected patients receiving lamivudine as component of anti-HIV regimen. Clinical Infections Diseases 32:963-969, 2001.

28. Hoofnagle JH. Hepatitis B - preventable and now treatable. The New England Journal of Medicine 345:1074-1076, 2006.

29. Hsu YS, Chren RN, Yeh CT. Long-term outcome after spontaneous HbeAg seroconversion in patients with chronic hepatitis B. Hepatology 35:1522-1527, 2002.

30. Janssen HL, Van Zonnveld M, Senturk H. Pegylated interferon alfa-2a alone or in combination with lamivudine for HbeAg-positive chronic hepatitis B: a randomised trial. Lancet 365:123-129, 2005.

31. Keefe EB, Dieterich DT, Han SB, Jacobson IM, Martin P, Schiff ER, Tobias H, Wright T. A treatment algorithm for the management of chronic hepatitis $B$ vírus infection in the United States: na update. Clinical Gastroenterology and Hepatology 2006 4:1-27, 2006.

32. Lacombe K, Gozian J, Boelle PY. Long-term hepatitis B virus dynamics in HIVhepatitis B virus-co-infected patients with tenofovir disoproxil fumarate. AIDS 19:907-915, 2005.

33. Lan GKK, Piratvisuth T, Luo KX, Marcellin P, Thongsawat S, Cooksley G, Gane E, Berg T, for the Peginterferon alfa-2a HbeAg positive chronic hepatitis B study group. Peginterferon alfa-2a, Lamivudine, and the combination for HbeAg-positive chronic Hepatitis B. The New England Journal of Medicine 352:2682-2695, 2005

34. Leung N, Gish RG, Wang C. A randomised double blind comparison of 3 doses of emtricitabine in patients with chronic hepatitis B given 48 weeks of treatment. Hepatology 34:349A.

35. Liaw YF, Leving N, Guan R. Asian-Pacific consensus statement on the management of chronic hepatitis B: a 2005 update. Liver International 25:472-489, 2005.

36. Liaw YF, Sung JJY, Chow WC. Lamivudine for patients with chronic hepatitis B and advanced liver disease. The New England Journal of Medicine 351:1521-1531, 2004 .

37. LLoeje VH, Yang HI, Su J. Predicting cirrosis risk based on the level of circulating hepatitis B viral load. Gastroenterology 130:678-686, 2006.

38. Locarnini S, Hatzakis A, Heathcote J. Management of antiviral resistance in patients with chronic hepatitis B. Antiviral Therapy 9:679-693, 2004.

39. Lok AS, McMahon B. Chronic hepatitis B: update of recommendations. Hepatology 39:857-861, 2004.

40. Marcellin P, Asselah T, Boyer N. Treatment of chronic hepatitis B. Journal of Viral Hepatitis 12:333-345, 2005.

41. Marcellin P, Chan TT, Lin SG, Tong MJ, Stievert W, Shiffman ML, Jeffers L, for the Adefovir Dipivoxil 437 study group: Adefovir dipivoxil for the treatment of hepatitis B e antigen-positive chronic hepatitis B. The New England Journal of Medicine 348:808-816, 2003.

42. Marcellin P, Lan GKK, Bonino F, Farci P, Hadziyannis S, Jin R. For the Peginterferon Alfa-2a HbeAg-negative chronic hepatitis B study group. The New England Journal of Medicine 351:1206-1217, 2004.

43. Marcellin P, Mommeja-Marin H, Sacks SL. A phase II dose escalating trial of clevudine in patients with chronic hepatitis B. Hepatology 40:140-148, 2004.

44. Matthews GV, Bartholomeusz A, Locarnini S. Characteristics of drug resistant $\mathrm{HBV}$ in an international collaborative study of HIV/HBV coinfected individuals on extended lamivudine therapy. AIDS 20:863-870, 2006.

45. Nunez M, Puoti M, Camino N, Soriano V. Treatment of chronic hepatitis B in human immunodeficiency virus-infected patients: present and future. Clinical Infections Diseases 37: 1678-1685, 2003.

46. Perrilo R, Hann HW, Mutiner D. Adefovir dipivoxil added to ongoing lamivudine in chronic hepatitis B with YMDD mutant hepatitis B virus. Gastroenterology 126:81-90, 2004. 
47. Pessoa M, Gazzard B, Huang A. Entecavir efficacy in HIV/HBV co-infected patients: safety and efficacy in a phase II study (ETV-038) [oral abstract 123]. In: Program and Abstracts of the $12^{\text {th }}$ Conference on Retroviruses and Opportunistic Infection (Boston). Foundation for Retrovirology and Human Health, Alexandria, VA 2005.

48. Peters M, Andeerson J, Lynch P. Tenofovir disoproxil fumarate is not inferior to adefovir dipivoxil for the treatement of hepatitis B virus in subjects who are coinfected with HIV: results of ACTG A5127. [Oral Abstract 124] In: 12 ${ }^{\text {th }}$ Abstract of Conference on Retroviruses and Opportunistic infections. Boston, MA, USA, p.124, 2005

49. Puoti M, Spinetti A, Ghezzi A. Mortality for liver disease in patients with HIV infection: a cohort study. Journal of Acquired Immunodeficiency Syndrome 24: 211-217, 2000

50. Realdi G, Fattovich G, Hadziyannis S. Survival and prognostic factors in 366 patients with compensated cirrhosis type B: a multicenter study. Journal of Hepatology 21:656-666, 1994.

51. Rector WG, Govindarajan S, Horsburgh CR. Hepatic inflammation, hepatitis B replication, and cellular immune function in homossexual males with chronic hepatitis B and antibody to human immunodeficiency virus. American Journal of Gatroenterology 83:262-266, 1988.

52. Salmon-Ceron D, Lewden C, Morlat P. Liver disease as a major cause of death among HIV infected patients: role of hepatitis $\mathrm{C}$ and $\mathrm{B}$ viruses and alcohol. Journal of Hepatology 42:799-805, 2005

53. Shaw T, Bartholomeusz A, Locarnini S. HBV drug resistance: mechanisms, detection and interpretation. Journal of Hepatology 44:593-606, 2006.

54. Sheldon JA, Camino N, Rodes B. Selection of hepatitis B virus polymerase mutations in HIV-coinfected patients treated with tenofovir. Antiviral Therapy 10: 727-734, 2005
55. Sheldon JA, Corral A, Rodes B. Risk of selecting K65R in antiretroviral-naive HIV-infected individuals with chronic hepatitis B treated with adefovir dipivoxil monotherapy. Hepatology 43:1385-1391, 2006.

56. Sherman M, Yurdaydin C, Soliano J. Entecavir for treatment of lamivuine-refratory, HBeAg-positive chronic hepatitis B. Gatroenterology 130:2039 - 2049, 2006.

57. Sherman M, Yurdaydin C, Sollano J, Silva M, Liaw YF, Cianciara J. Entecavir for the treatment of lamivudine-refractory, HbeAg-positive chronic hepatitis B. Gastroenterology 130:2039-2049, 2006.

58. Simpson ND, Simpson PW, Ahmed AM. Prophylaxis against chemotherapy-induced reactivation of hepatitis B virus infection with lamivudine. Journal of Clinical Gastroenterology 37:68-71, 2003.

59. Sulkowski MS, Thomas DL, Chaisson RE, Moore RD. Hepatotoxicity associated with antiretroviral therapy in adults infected with human immunodeficiency virus and the role of hepatitis C ou B virus infection. JAMA 283: 74-80, 2000.

60. Thio CL, Seaberg EC, Skolasky Jr R. HIV-1, hepatitis B virus and risk of liver-related mortality in the Multicenter Cohort Study (MACS). Lancet 360: 1921-1936, 2002.

61. Thomas DL, Cannon RO, Shapiro CN. Hepatitis C, hepatitis B and human immunodeficiency virus infections among non-intravenous drug using patients attending clinics for sexually transmitted diseases. Journal of Infections Diseases 169:990-995, 1994

62. Webster GJ, Reignat S, Maini MK. Incubation phase of acute hepatitis B in man: dynamic of cellular immune mechanisms. Hepatology 32: 1117-1124, 2000.

63. Yang HI, Lu SN, Liaw YF, You SL, Sun CA, Wang LY, Hsiao CK, Chen PJ, Chen DS, Chen CJ, for the Taiwan Community-based cancer screening project group. Hepatitis B e antigen and the risk of hepatocellular carcinoma. The New England Journal of Medicine 347:168-174, 2002.

64. Zoulim F. Assessment of treatment efficacy in HBV infection and disease. Journal of Hepatology 44:95-99, 2006. 